\title{
Principais riscos e fatores de risco ocupacionais dos marceneiros e carpinteiros, bem como doenças profissionais associadas e medidas de proteção recomendadas
}

TIPO DE ARTIGO: Revisão Bibliográfica Integrativa

AUTORES: Santos M,(1) Almeida A.(2)

\section{RESUMO}

\section{Introdução/ enquadramento/ objetivos}

Os profissionais a trabalhar em equipas de Saúde Ocupacional, mesmo que não diretamente ligados ao setor da Marcenaria/ Carpintaria, podem receber trabalhadores com esses antecedentes laborais, pelo que poderão sentir necessidade de aprofundar um pouco os seus conhecimentos na área. Os marceneiros e carpinteiros estão expostos a inúmeros riscos/ fatores de risco. Contudo, apesar da gravidade de alguns destes, a generalidade dos trabalhadores desconhece ou banaliza o impacto que poderá existir na sua saúde e segurança. Para além disso, a generalidade da bibliografia consultada aborda riscos específicos e parcelares, não sendo fácil encontrar uma perspetiva global, a nível de Saúde Ocupacional. Pretende-se com esta revisão bibliográfica resumir o que de mais recente e pertinente se publicou sobre o tema.

\section{Metodologia}

Pergunta protocolar: Quais os principais riscos e fatores de risco existentes para os marceneiros e carpinteiros, doenças profissionais associadas e medidas de proteção recomendadas?

Foi realizada uma pesquisa bibliográfica em junho de 2015 nas bases de dados "CINALH plus with full text, Medline with full text, Database of Abstracts of Reviews of Effects, Cochrane Central Register of Controlled Trials, Cochrane Database of Systematic Reviews, Cochrane Methodology Register, Nursing and Allied Health Collection: comprehensive, MedicLatina, Academic Search Complete" e RCAAP.

\section{Conteúdo}

Os marceneiros e carpinteiros estão expostos a inúmeros riscos/ fatores de risco; destacam-se o contato com as partículas derivadas da madeira, bem como com agentes químicos (e eventuais alterações oncológicas, respiratórias, imunoalérgicas e dermatológicas), cargas (e eventuais lesões musculo-esqueléticas- LMEs), queda de objetos e ao mesmo nível (e eventuais entorses ou fraturas), postura de pé mantida, utilização de máquinas perigosas (quer pela probabilidade e gravidade de acidente, quer pelo ruido e vibrações produzidas), entrada de partículas a nível ocular e, em alguns casos, eventual desconforto térmico e baixa iluminância.

\section{Conclusões}

$\mathrm{Na}$ bibliografia consultada são mencionadas diversas medidas de proteção coletiva aplicáveis a este setor. A nível de medidas de proteção individual são realçados a máscara com filtro adequado, luvas, óculos, fato/ farda, calçado com reforço superior de aço e a proteção auricular.

Para além da patologia oncológica, também podem ser consideradas doenças profissionais neste setor a dermatite, urticária, conjuntivite, rinite, asma, pneumonite por hipersensibilidade e a alveolite alérgica intrínseca. 
marceneiro e carpinteiro.

\section{INTRODUÇÃO/ ENQUADRAMENTO/ OBJETIVOS}

Os profissionais a trabalhar em equipas de Saúde Ocupacional, mesmo não diretamente ligados ao setor da Marcenaria e Carpintaria, podem receber trabalhadores com esses antecedentes laborais, pelo que poderão sentir necessidade de aprofundar um pouco os seus conhecimentos na área.

Os marceneiros e carpinteiros estão expostos a inúmeros riscos/ fatores de risco. Contudo, apesar da gravidade de algumas situações, a generalidade dos trabalhadores desconhece ou banaliza o impacto que poderá existir na sua saúde e segurança. Para além disso, a generalidade da bibliografia consultada aborda riscos específicos e parcelares, não sendo fácil encontrar uma perspetiva global, a nível de Saúde Ocupacional. Pretende-se com esta revisão bibliográfica resumir o que de mais recente e pertinente se publicou sobre o tema.

\section{METODOLOGIA}

Pergunta protocolar: Quais os principais riscos e fatores de risco existentes para os marceneiros e carpinteiros, doenças profissionais associadas e medidas de proteção recomendadas?

Em função da Metodologia PICo foram considerados:

-P (population): marceneiros e carpinteiros

-I (interest): adquirir mais conhecimentos sobre os principais riscos e fatores de risco existentes para os profissionais da marcenaria e carpintaria, eventuais doenças profissionais associadas e medidas de proteção recomendadas, segundo os dados mais recentemente publicados

-C (context): saúde ocupacional nas empresas de marcenaria e carpintaria

Foi realizada uma pesquisa bibliográfica em junho de 2015 nas bases de dados "CINALH plus with full text, Medline with full text, Database of Abstracts of Reviews of Effects, Cochrane Central Register of Controlled Trials, Cochrane Database of Systematic Reviews, Cochrane Methodology Register, Nursing and Allied Health Collection: comprehensive, MedicLatina e Academic Search Complete". Utilizando as palavras e expressões-chave "joiner", "carpenter", "furniture worker" e "furniture industry" foram obtidos 0, 1, 12 e 40 artigos, respetivamente, com os critérios publicação igual ou superior a 2005 e acesso a texto completo; em função da língua original (portuguesa, inglesa ou espanhola) e da pertinência para o objetivo desta revisão, foram selecionados $0,1,4$ e 11 artigos, respetivamente, após a leitura do título e resumo. Por sua vez, após a leitura na íntegra, seis artigos foram excluídos por não serem pertinentes para os objetivos desta revisão.

Contudo, como praticamente não se encontram estudos relativos à realidade portuguesa nestas bases de dados indexadas, os autores procuraram trabalhos inseridos na base RCAAP (Repositório Científico de Acesso Aberto em Portugal). Aqui, utilizando as palavras-chave "marceneiros" e "carpinteiros", foram obtidos 4 e 136 documentos; após a leitura dos resumos e artigos foram selecionados 3 e 2 exemplares (os artigos excluídos não se demonstraram pertinentes para o objetivo desta revisão).

O resumo da metodologia aplicada na realização desta revisão bibliográfica pode ser consultado no Fluxograma $\left(1^{\mathrm{a}}\right.$ e $2^{\mathrm{a}}$ fases). A caraterização metodológica e resumo dos artigos selecionados pode ser consultada no Quadro 1.

\section{CONTÉUDO}

Os marceneiros e carpinteiros estão expostos a inúmeros riscos/ fatores de risco; destacam-se o contato com as partículas derivadas da madeira e agentes químicos ${ }^{1,2}$ (e eventuais alterações oncológicas, respiratórias, imunoalérgicas e dermatológicas), cargas (e eventuais lesões músculo-esqueléticas- LMEs), queda de objetos e ao mesmo nível (e eventuais entorses ou fraturas), postura de pé mantida, utilização de máquinas perigosas (quer pela probabilidade e gravidade de acidente, quer pelo ruido e vibrações produzidas), entrada de partículas a nível ocular, bem como eventuais desconforto térmico e baixa iluminância ${ }^{2}$.

\section{Partículas derivadas da madeira}

Cerca de 3,6 milhões de trabalhadores europeus estão/ estiveram expostos aos derivados da madeira, de forma regular $^{3-6}$; sobretudo na Alemanha, Espanha, Reino Unido, Itália, Polónia e França; Portugal surge em nono lugar ${ }^{6}$. Contudo, 
só na Índia, por exemplo, o número estimado é equivalente ao de todo continente europeu (3,5 milhões $)^{7}$. Mundialmente, por sua vez, outros investigadores estimam que existam cerca de dois milhões de indivíduos expostos diariamente ${ }^{8}$.

Os marceneiros e os carpinteiros são os dois grupos profissionais mais expostos às partículas derivadas da madeira, sobretudo devido às máquinas que utilizam, geralmente em ambientes fechados e/ou com ventilação desadequada. As áreas com maior risco são a da construção e a de fabrico de móveis; pois a exposição na exploração florestal e construção naval é mais discreta. O impacto na saúde dependerá sobretudo do tipo de madeira e produtos químicos nela utilizados, bem como da intensidade e cronicidade da exposição ${ }^{6}$. Para além disso, máquinas totalmente automatizadas trabalham geralmente a uma velocidade superior, pelo que geram e dispersam mais poeiras ${ }^{5}$, ainda que existam menos trabalhadores expostos na proximidade.

A poeira resultante da madeira é uma mistura complexa constituída por celulose, polioses (mistura de polímeros e polissacarídeos de baixa massa molecular) e linhanos; estas substâncias passam a constituir um problema médico quando conseguem circular via aérea e depositar-se no nariz, orofaringe ou outras áreas do aparelho respiratório ${ }^{7}$. A concentração em ambientes fechados estará correlacionada com a ventilação ${ }^{5,9}$, métodos de limpeza e a evicção do uso de ar comprimido. Um estudo brasileiro, por exemplo, estimou que apenas $12 \%$ das empresas estudadas tinham funcionários específicos para a limpeza, ou seja, na generalidade dos casos esta era executada pelos marceneiros e ajudantes ${ }^{10}$.

O contato com partículas orgânicas pode causar sintomas irritativos e/ ou alérgicos; após a inalação as partículas podem ser depositadas nas vias respiratórias, em função do seu diâmetro, agregação/ aglomeração e comportamento no ar. As atividades de modelagem e lixagem estão associadas a níveis mais elevados de exposição (devido às partículas produzidas terem menor dimensão)- por sua vez, os processos que envolvem o corte da madeira já produzem partículas maiores; para além disso, o tipo e a quantidade de partículas produzidas também depende da densidade da madeira 6 .

Na realização das provas de função respiratória é frequente encontrar diminuição de alguns parâmetros 4, 8, 11, 12, 13, sobretudo nos profissionais mais expostos ${ }^{4,11}$ e à medida que o turno progride ${ }^{11}$. A diminuição da capacidade pulmonar associa-se à irritação mecânica e/ ou química do tecido pulmonar, tendo como consequência a diminuição do calibre das vias respiratórias e diminuição da concentração de oxigénio. Alguns autores defendem até a possibilidade de, a longo prazo, existir probabilidade aumentada de surgir uma doença pulmonar crónica obstrutiva ${ }^{6}$.

A pneumonite por hipersensibilidade ocorre quando partículas de pequena dimensão se alojam nas vias aéreas, originando uma reação alérgica; 6,13 nesta realça-se também o contributo associado aos fungos e bactérias presentes em algumas madeiras. O início da semiologia pode ser tão breve quanto horas ou dias, sendo a situação facilmente confundida com infeção respiratória viral. Com a cronicidade da exposição os estragos poderão tornar-se irreversíveis ${ }^{6}$.

Algumas madeiras podem desencadear sintomas alérgicos, como é o caso do pinho, faia ${ }^{3,4}$, pau de marfim ${ }^{3}$ e o cedro vermelho $3,4,6$. Outros autores também destacam o carvalho, pau-brasil, abeto e o pinheiro; bem como a madeira zebra africana, mogno, teca, maple africano, abachi/ obeche, abiruana, buxo, cocobolo, froko, kamballa, keja/ muninga, limba, mansónia, amoreira, ramin e ukola 6 . Alguns investigadores defendem a possibilidade de existir reatividade cruzada entre os diversos alérgenos ${ }^{3}$. A semiologia mais frequente é caraterizada por irritação ocular (prurido- "comichão" e eritema"vermelhidão") ${ }^{8}$, obstrução nasal a alternar com rinorreia (fluxo nasal) $)^{6,8}$, irritação da mucosa nasal ${ }^{3,4,6,11}$, espirros, tosse e dispneia (dificuldade respiratória). A alergia secundária ao contato com a madeira associa-se não só aos constituintes desta, mas também aos produtos químicos ${ }^{6,13}$ e eventuais agentes biológicos presentes ${ }^{6}$.

A semiologia mais caraterística da asma é a dispneia, pieira (respiração ruidosa), tosse e toracalgia (desconforto torácico); geralmente inicia-se algumas horas após a exposição. Em alguns casos as vias respiratórias podem ficar hipersensibilizadas, pelo que ficam mais reativas com a mesma intensidade de exposição ou igualmente reativas com menor exposição. As madeiras mais frequentemente associadas a esta condição são os cedros vermelho ocidental e o branco oriental, madeira vermelha da califórnia, sequoia, cedro do líbano, carvalho, abeto, pinho, freixo e o mogno. Alguns investigadores estimaram, por exemplo, que a prevalência de asma nos trabalhadores expostos ao cedro vermelho poderá ir até os $13,5 \%$, sendo o risco dose-dependente ${ }^{6}$.

Para além da asma ${ }^{3-5}, 12,13$, existem estudos onde se verificou um aumento na prevalência da alveolite alérgica ${ }^{11}$, bronquite $^{11,12}$, rinite $^{3,11}$, conjuntivite ${ }^{11}$ e até cancro sino-sinusal ${ }^{11,12}$ Aliás a IARC- International Agency for Research on 
Cancer- considera que as poeiras derivadas da madeira são carcinogénicas em humanos $3,5,6,8,11$. As principais neoplasias destacadas são o adenocarcinoma das cavidades nasais e seios perinasais ${ }^{6,7}$; outros investigadores também mencionam o cancro do pulmão, faringe, estômago e colón. O uso de máscaras de pano não proporciona qualquer proteção neste contexto ${ }^{7}$, apesar de serem utilizadas em alguns países ${ }^{11}$. Em 1987 a IARC tinha assinalado que as patologias oncológicas mais frequentemente associadas à exposição à madeira eram os tumores nasais e perinasais, linfomas, leucemias, sarcomas dos tecidos moles da faringe/ laringe, pulmão, estômago e doença de Hodking; posteriormente considerou que o risco estava provado com clareza apenas para as primeiras duas situações. Algumas normas não fazem distinção entre madeiras duras e macias, no contexto oncológico; contudo, a incidência de cancro nasal nos EUA é substancialmente menor que noutros países como, por exemplo, a Grã-Bretanha, eventualmente pelo tipo de madeiras utilizadas- supõem alguns autores. Ainda assim, genericamente, ao longo das décadas, verificou-se uma diminuição da incidência desta patologia. Ainda segundo a IARC, o cancro naso-sinusal está associado sobretudo à faia e ao carvalho ${ }^{6}$.

Quanto a este fator de risco, a NIOSH (United States National Institute of Occupational Safety and Health) recomenda que não se ultrapasse o nível de $1 \mathrm{mg} / \mathrm{m}^{3}$ na atmosfera de trabalho, para turnos de oito horas; contudo, na Turquia e na União Europeia, por exemplo, esse cut-off é cinco vezes superior ${ }^{8}$. Num estudo brasileiro, por exemplo, $63 \%$ dos marceneiros entrevistados consideravam subjetivamente que o nível de poeiras no ambiente de trabalho era excessivo e $16 \%$ sentia-se particularmente incomodado em função de queixas respiratórias associadas. $67 \%$ desta amostra também considerava subjetivamente que a ventilação não era adequada ${ }^{14}$. No contexto europeu, considerava-se que $16 \%$ dos expostos atingia um nível superior a $5 \mathrm{mg} / \mathrm{m}^{3}$ e $37 \%$ estava entre 1 e $1,5 \mathrm{mg} / \mathrm{m}^{3}$ (o que se considera pouco significativo a nível médico). Contudo, estas estimativas podem ser comprometidas quando o mesmo indivíduo está exposto a diferentes tipos de madeira, situação essa razoavelmente frequente ${ }^{6}$.

Para caraterizar a realidade portuguesa, foi realizado um estudo entre 2000 e 2003, que estimou que cerca de 110.000 trabalhadores portugueses estavam expostos a partículas de madeira, ou seja, cerca de $2,7 \%$ da população ativa; subdivididos sobretudo por 49.000 na indústria do mobiliário, 15.000 na carpintaria associada à construção civil, 10.000 em serrações, 3.000 a trabalhar com placas de madeira e 11.000 na área florestal. Os níveis mais elevados de exposição foram encontrados na atividade de fabrico de móveis; neste contexto, o pinho parece ser a madeira macia mais utilizada. Cerca de $14,5 \%$ dos profissionais expostos (16.000 indivíduos) têm um nível superior a $5 \mathrm{mg} / \mathrm{m}^{3}$; contudo, $22 \%$ não atingiam $0,5 \mathrm{mg} / \mathrm{m}^{3}$; ou seja, a exposição é muito frequente, mas na generalidade dos casos não é ultrapassado o limite imposto nas normas europeias. Uma estimativa anterior (de 1990 a 1993) calculava que existissem 85.000 trabalhadores portugueses expostos aos derivados da madeira ${ }^{6}$.

\section{Agentes químicos}

Em alguns setores da indústria da madeira são utilizados solventes (tintas, vernizes, colas e lacas) 1, 4, 10; que contêm tolueno, benzeno e/ou xileno ${ }^{1}$. Para além disso, podem ser adicionados à madeira alguns produtos, para dar resistência aos microrganismos e maior durabilidade, como é o caso do arsénio, crómio, cobre, creosoto, pentaclorofenol, formaldeído e fenol $^{6}$. As principais consequências na saúde humana são cognitivas, neurológicas e emocionais, ou seja: diminuição da memória, anosmia (alteração no olfato), cefaleia, vertigem, alterações nos reflexos, palpitações, bem como eventual euforia e ansiedade. Outros investigadores defendem também a existência de um efeito carcinogénico em algumas situações ${ }^{1}$.

Num estudo brasileiro, por exemplo, $21,4 \%$ dos marceneiros avaliados referia dispneia noturna que associava subjetivamente aos agentes químicos laborais ${ }^{10}$.

\section{Agentes biológicos}

A madeira pode conter microrganismos (como fungos) e/ ou as respetivas toxinas $6,8,12$, sobretudo na casca $^{6}$, originando a síndroma tóxica associada a poeiras orgânicas ${ }^{12}$. O risco aumenta durante o processamento da madeira, quando estes elementos passam a circular via aérea6.

\section{Cargas/ LMEs}

Estudos brasileiros avaliaram a existência de algias em marceneiros e verificaram que as queixas eram mais frequentes nos membros superiores ${ }^{14}$, coluna ${ }^{10,14}$ e membros inferiores ${ }^{13}$. Outra investigação também destacou (para além 
do manuseamento de cargas, por vezes, muito elevadas) a repetição do movimento em algumas tarefas como, por exemplo, no aparafusamento de dobradiças ${ }^{10}$.

\section{Queda de objetos e queda ao mesmo nível}

Dado estes profissionais trabalharem com peças, por vezes, de elevadas dimensões e carga; em caso de queda em cima do trabalhador, geralmente surgem consequências médicas relevantes. Por sua vez, dado no chão ser frequente a existência de madeiras e ferramentas, também não é rara a queda ao mesmo nível (ainda que nenhum artigo na bibliografia selecionada tenha destacado tal com clareza).

\section{Postura de pé mantida}

A generalidade das tarefas destes profissionais é executada de pé e geralmente num contexto mais estático que dinâmico, pelo que tal poderá ter consequências músculo-esqueléticas e/ou vasculares (ainda que nenhum trabalho entre os inseridos nesta revisão tenha registado tal diretamente).

\section{Máquinas perigosas- acidentes}

A generalidade das máquinas utilizadas neste setor profissional, além de produzir ruído e vibrações, tem a capacidade de causar acidentes graves. Num estudo brasileiro, por exemplo, a maioria dos marceneiros $(59,5 \%)$ considerava que a lixadeira era a máquina mais fácil de utilizar e a menos perigosa $(50 \%)$; por sua vez, a tupia era vista como a mais difícil $(61,9 \%)$ e simultaneamente a mais perigosa $(73,8 \%)^{10}$.

\section{Ruído}

A generalidade dos países considera como "aceitável" a exposição até os 85 dBA. Acredita-se que o ruído induz a produção de radicais livres que irão diminuir a circulação sanguínea coclear. Quando a exposição laboral é continuada, a hipoacusia (diminuição da audição) é mais notória, uma vez que fica diminuído o tempo de recuperação disponível ${ }^{15}$. Esta questão representa uma parte substancial das doenças profissionais na generalidade dos países, à qual se associa um custo avultado, quer económico, quer social (devido a alterações emocionais, maior risco de acidentes e menor qualidade de vida geral). Para além da hipoacusia, também podem surgir acufenos (zumbidos) ${ }^{15}$.

Nos últimos anos têm sido publicados artigos que alertam para a possibilidade do ruído também se associar a várias alterações cardiovasculares (como hipertensão arterial, taquicardia e isquemia do miocárdio), alterações do sono, respiratórias (asma), obstétricas (aborto espontâneo) e imunológicas; bem como consequências a nível do desempenho e variáveis psicológicas (ansiedade, irritabilidade, depressão, desorientação, alteração na capacidade concentração e de aprendizagem). A explicação fisiopatológica reside no facto de o ruído atuar como agressor no sistema nervoso autónomo e, consequentemente, no sistema endócrino (ainda que nenhum dos trabalhos utilizados nesta revisão tenha mencionado tal de forma explícita).

As frequências de som atingidas pela hipoacusia com maior frequência situam-se entre os 3000 e os $6000 \mathrm{Hzs}$, com destaque para os 4000 ou 6000 , consoante os autores ${ }^{15}$.

Um estudo brasileiro avaliou a exposição ao ruído em marcenarias e concluiu que várias máquinas ultrapassavam os decibéis registados na generalidade das normas e legislação; por exemplo, o traçador atingia cerca de $95 \mathrm{~dB}(\mathrm{~A})$, a tupia e a serra circular 89 e a desempenadeira e a desengrossadeira $88 \mathrm{~dB}(A)^{14}$. Outro estudo nesse país, entre carpinteiros, concluiu que $44 \%$ da amostra estudada apresentava hipoacusia (sendo que $74 \%$ destes de forma bilateral); esta demonstrou-se mais frequente em idades mais avançadas e nos indivíduos com maior número de anos de exposição ao ruido. Neste estudo, a generalidade das máquinas utilizadas emitia ruido na ordem dos 81 a $115 \mathrm{~dB}(\mathrm{~A})^{15}$.

\section{Vibrações}

A vibração pode ser definida como movimento oscilatório, que implica uma alteração da velocidade e direção do deslocamento ("vai e vem"). As vibrações com exposição breve levam a alterações fisiológicas minor, a exposição crónica, por sua vez, poderá levar a lesões irreversíveis.

Num estudo brasileiro, por exemplo, $64 \%$ dos marceneiros avaliados afirmavam sentir vibrações, sendo que $47 \%$ as 
considerava subjetivamente excessivas; destacando a tupia, serra circular, desengrossadeira e a desempenadeira ${ }^{14}$.

\section{Desconforto térmico}

A existência de desconforto térmico diminui a produtividade e satisfação do trabalhador, aumentando também o risco de acidente, em alguns casos. Contudo, um estudo brasileiro avaliou o ambiente de trabalho em marcenarias e concluiu que não existia desconforto térmico significativo na amostra estudada, em função nas normas em vigor nesse país ${ }^{14}$.

\section{Baixa iluminância}

Um estudo brasileiro avaliou a iluminância existente em marcenarias e concluiu que esta era inferior às normas nacionais em vigor; sendo a iluminação fundamental para atenuar a fadiga visual e alguns acidentes. Para além disso, a acuidade visual também poderá ficar prejudicada pelos níveis elevados de poeiras a circular ${ }^{14}$.

\section{Medidas de proteção coletiva}

Estas englobam a modernização/ automatização das máquinas, o encapsulamento na fonte, ventilação adequada, rotatividade, vigilância para a saúde dos trabalhadores, troca por produtos menos tóxicos (quando possível), instalações que proporcionem uma correta lavagem das mãos e limpeza adequada (por exemplo, não utilizar ar comprimido mas aspiração por vácuo), fichas de segurança disponíveis e formação ${ }^{6}$; para além disso, e apesar de não mencionadas diretamente na bibliografia consultada, também poderá considerar-se a execução das tarefas mais problemáticas nos momentos em que estão menos funcionários presentes, bem como limitar a sua permanência nas áreas e momentos com maior risco.

A generalidade dos marceneiros inicia a sua atividade profissional como ajudante, aprendendo informalmente com colegas mais velhos, ou seja, muito poucos têm a oportunidade de receber cursos de formação especializados ${ }^{10,14}$. Alguns investigadores da área realçam a necessidade de consciencializar os empregadores relativamente à importância dos benefícios da saúde ocupacional e respetiva formação associada. Aliás, num estudo brasileiro, estimou-se que $94,1 \%$ das marcenarias estudadas nunca tinha disponibilizado cursos de segurança no trabalho, devido ao custo e/ ou à falta de informação sobre que instituições os poderiam organizar ${ }^{10}$.

\section{Medidas de proteção individual}

Aqui destacam-se o uso de máscara com filtro adequado, luvas, óculos, fato/ farda, calçado com reforço superior de aço e proteção auricular 6 .

Um estudo brasileiro quantificou que $67 \%$ das empresas englobadas na amostra disponibilizavam EPIs, mas nenhuma exigia obrigatoriedade de uso. Neste contexto, a proteção auricular e os óculos eram os melhor aceites pelos trabalhadores, ao contrário das luvas e da máscara (aos quais associavam maior desconforto) ${ }^{14}$. Noutro estudo desse país, $92,8 \%$ dos entrevistados considerava que era justamente a proteção auricular o EPI mais incomodativo (pelo aumento da temperatura e por apertar o ouvido); a máscara foi considerada o segundo EPI mais incomodativo, pela suposta dificuldade respiratória associada. Contudo, para 7,2\% dos marceneiros estudados nenhum EPI causava desconforto. Mas nesta investigação 5,8\% dos empregados não usavam qualquer EPI (porque não sentiam essa necessidade); contudo, 11,9\% utilizavam-nos durante todo o turno; $30,9 \%$ utilizava apenas a proteção auricular e/ ou máscara quando estavam em máquinas e $54,8 \%$ utilizavam pontualmente (quando se lembravam) ${ }^{10}$.

\section{Sinistralidade}

Dois estudos brasileiros estimaram que $66 \%{ }^{14}$ a $78,6 \%{ }^{10}$ dos marceneiros estudados já tinham tido algum acidente laboral. As zonas do corpo mais atingidas era a dos dedos ${ }^{10,14}$ e mãos ${ }^{10}$; as máquinas mais frequentemente envolvidas foram a tupia, serra circular e a desempenadeira ${ }^{14}$. Contudo, os cortes só foram profundos em cerca de $9 \%$ das situações; ainda que $7,1 \%$ já tenha assistido a mutilações dos dedos de colegas. Outro acidente razoavelmente frequente foi a queda de móveis ou tábuas nos pés $(4,8 \% \text { dos marceneiros })^{10}$, bem como entrada de corpos estranhos, sobretudo a nível ocular.

\section{Doenças profissionais}

Para além da patologia oncológica, também podem ser consideradas doenças profissionais neste setor a dermatite, urticária, conjuntivite, rinite, asma, pneumonite por hipersensibilidade e a alveolite alérgica intrínseca ${ }^{6}$, atrás mencionadas. 
A dermatite, por exemplo, pode ocorrer por irritação mecânica, contato com os agentes químicos, com os derivados da madeira e/ou com os microrganismos nela existentes. As madeiras que mais frequentemente se associam a alterações neste contexto são a guarea, mogno africano, iroko, cambala, teca africana, abeto, cedro vermelho do este, cedro de incenso, abeto, pinho, douglásia, cedro branco do norte, cicuta, satin da índia de este e oeste, olon, moah, mahwa, mackre, baku, mansónia, teixo, nogueira preta africana, olmo e a teca 6 .

No quadro 2 estão resumidos dados relativamente às principais madeiras utilizadas em diversos países, respetiva utilização prática e principais efeitos conhecidos a nível da saúde.

\section{CONCLUSÕES}

A generalidade dos trabalhadores deste setor profissional não se apercebe da importância ou intensidade de alguns riscos, pelo que, por vezes, menospreza algumas medidas de proteção coletiva e/ ou individual. A formação profissional terá eventualmente hipótese de sensibilizar funcionários e chefias e assim poder-se-ão obter melhorias a nível de sinistralidade, doenças profissionais e qualidade de vida geral.

Os principais riscos/ fatores de risco laborais deste setor são o contato com os derivados da madeira, a utilização de máquinas com probabilidade razoável de causarem acidentes com alguma gravidade, bem como o manuseamento de cargas, queda de objetos, lesões músculo-esqueléticas, ruido, vibrações, agentes químicos e agentes biológicos.

Na bibliografia consultada são mencionadas diversas medidas de proteção coletiva aplicáveis a este setor. A nível de medidas de proteção individual são realçados a máscara com filtro adequado, luvas, óculos, fato/ farda, calçado com reforço superior de aço e a proteção auricular.

As principais doenças profissionais estão associadas à patologia oncológica nasal e dos seios perinasais, bem como asma, pneumonite por hipersensibilidade, dermatite, urticária, conjuntivite, rinite, asma e a alveolite alérgica intrínseca.

Não só os dados apresentados nesta revisão reúnem de forma muito sucinta o que de mais recente se publicou sobre a saúde laboral neste setor (em português e utilizando artigos que abordavam aspetos muito parcelares e escritos noutras línguas), de forma a proporcionar um fácil acesso a esta informação da parte dos profissionais que se iniciem neste setor; como também se percebeu que a realidade portuguesa não está suficientemente retratada, pelo que seria pertinente motivar os profissionais da saúde ocupacional que trabalham no ramo (ou venham a trabalhar) para investigar aspetos relevantes do tema, divulgando as conclusões obtidas através da publicação de artigos.

\section{CONFLITOS DE INTERESSE, QUESTÕES ÉTICAS E/OU LEGAIS}

Nada a declarar.

\section{AGRADECIMENTOS}

Nada a declarar.

\section{BIBLIOGRAFIA}

1)Mandiracioglu A, Akgur S, Kocabiyik N, Sener U. Evaluation of neuropsychological symptoms and exposure to benzene, toluene and xylene among two different furniture worker groups in Izmin. Toxicology and Industrial Health. 2011, 27(9), 802809.

2)Alves L. Identificação e avaliação de riscos- Carpintaria Francisco Lopes e filhos. Pós-graduação em Segurança e Higiene no Trabalho. RCAAP. 2013, 1-80.

3)Schlunssen V, Kespohl S, Jacobsen G, Raulf-Heimsoth M, Sigsgaardt T. Immunoglobulin E-mediated sensitization to pine and beech dust in relation to wood dust exposure levels and respiratory symptoms in the furniture industry. Scandinavian Journal of Work, Environmental \& Health. 2011, 37 (2), 159- 167.

4)Sripaiboonkij P, Phanprasit W, Jaakklola M. Respiratory and skin effects of exposure to wood dust from the rubber tree hevea brasiliensis. Occupational and Environmental Medicine. 2009, 66, 442-447. 
5)Schulunssen V, Jacobsen G, Erlandsen M, Mikkelsen A, Schaumburg I, Sigsgaard T. Determinants of wood dust exposure in the Danish furniture industry- results from two cross- sectional studies 6 years apart. Annals of Occupational Hygiene. 2008, 52(4), 227-238.

6)Amaral A. Exposição a partículas e eventual efeito sobre a saúde. Instituto Politécnico de Lisboa; Escola Superior de Tecnologia de Saúde de Lisboa. RCAAP. 2012, 1-124.

7)Rekhadevi P, Mahboob M, Rahman M, Grover P. Genetic damage in wood dust-exposed workers. Mutagenesis. 2009, 24(1), 59-65.

8)Osman E, Pala K. Occupational exposure to wood dust and health effects on the respiratory system in a minor industrial estate in Bursa/ Turkey. International Journal of Occupational Medicine and Environmental Health. 2009, 22(1), 43-50.

9)Hagstom K, Jacobson G, Sigsgaard T, Schaumburg I, Erlandsen M, Schunssen V. Predictors of monoterpene exposure in the Danish furniture industry. Annals of Occupational Hygiene. 2012, 56(3), 253-263.

10)Silva K, Souza A, Minetti L. Avaliação do perfil de trabalhadores e das condições de trabalho em marceneiros no município de Viçosa- MG. SI- RCAAP. 2002, 26(6), 769-775.

11)Sriproed S, Osni $P$, Sujurarat $D$, Chantanakul $S$, Harncharoen $K$, Ong-Artborirak $P$ et al. Respiratory effects among rubberwood furniture factory workers in Thailand. Archives of Environmental and Occupational Health. 2013, 68(2), 87-95.

12)Kalliny M, Brisolara J, Glindmeyer H, Rando R. A survey of size-fractionated dust levels in the U.S. wood processing industry. Journal of Occupational and Environmental Hygiene. 2008, 5, 501-510.

13)Aprajuta M, Panwar N. Effect of wood dust on respiratory health status of carpenters. Journal of Clinical and Diagnostic Research. 2013, 7(8), 1589-1591.

14)Fiedler $N$, Guimarães $P$, Alves $R$, Wanderley $F$. Avaliação ergonómica do ambiente de trabalho em marceneiros no sul do Espírito Santos. SIF- RCAAP. 2010, 34(5), 907-915.

15) Farias $V$, Buriti $A$, Rosa M. Ocorrência de perda auditiva induzida pelo ruído em carpinteiros. CEFAC. 2012, 14(3), $413-422$.

Fluxograma $1^{\text {a }}$ fase

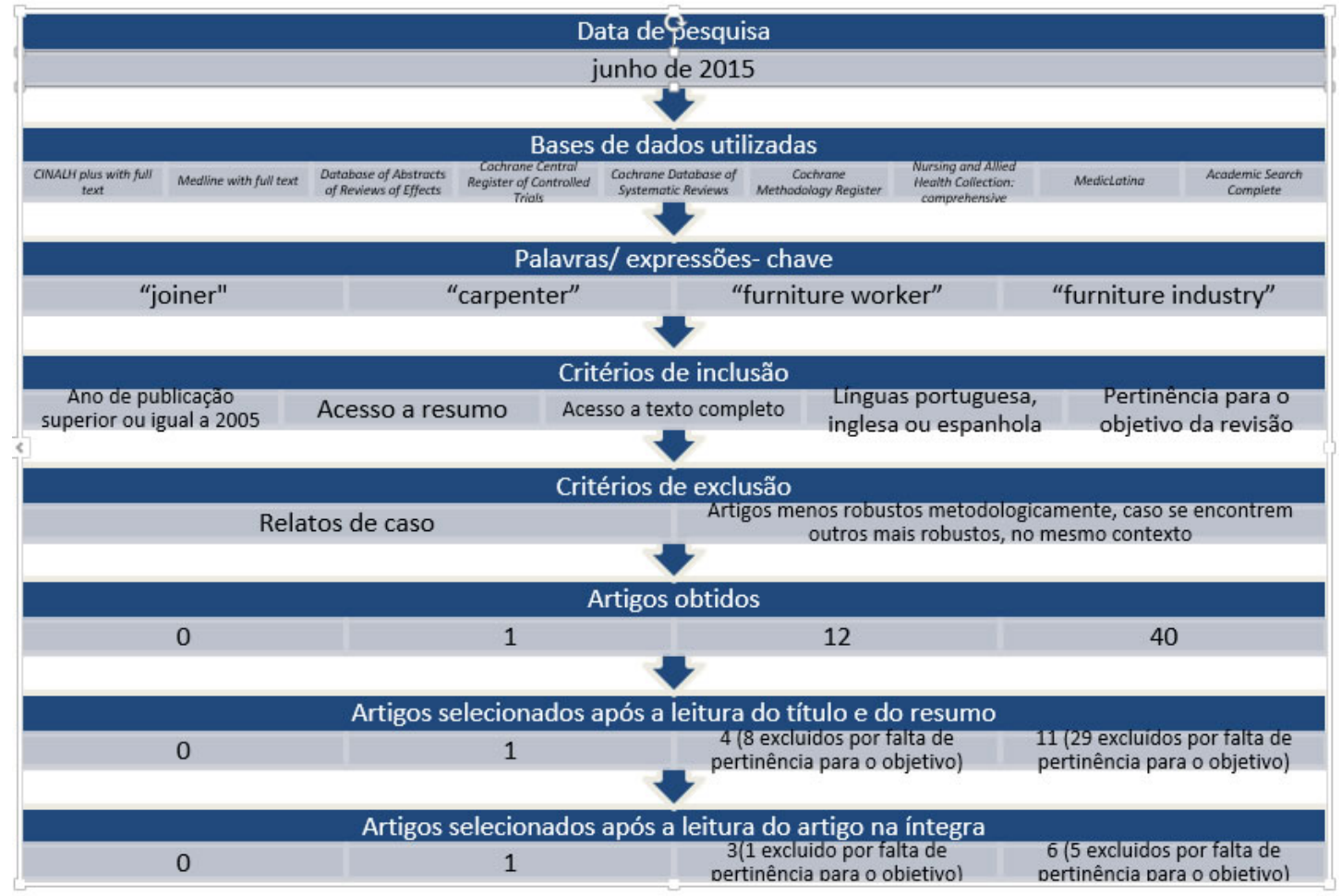

Fluxograma $2^{\mathrm{a}}$ fase 


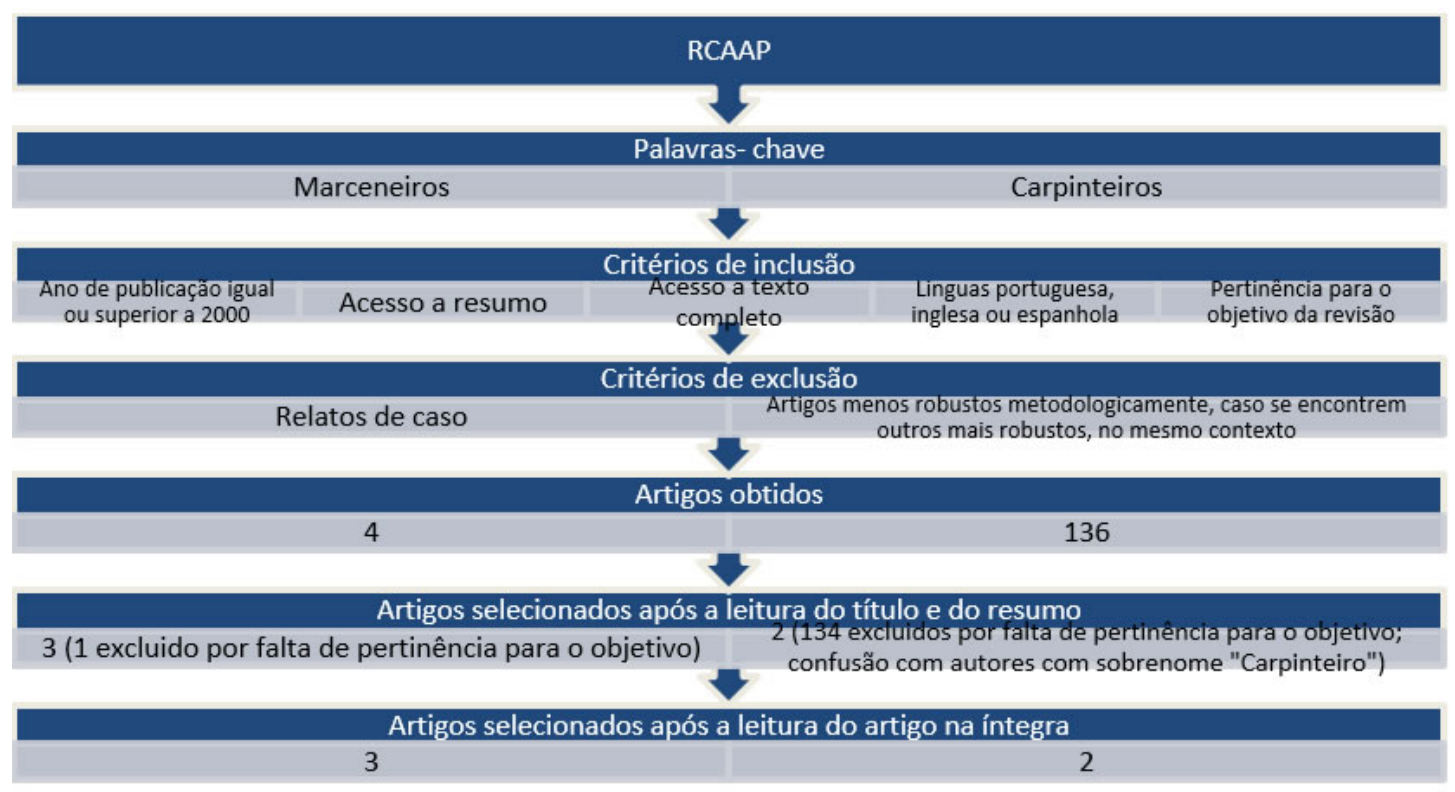

Quadro 1- Classificação metodológica dos artigos consultados

\begin{tabular}{|l|l|}
\hline Artigo & $\begin{array}{l}\text { Tipo de } \\
\text { estudo }\end{array}$ \\
\hline 1 & $\begin{array}{l}\text { Observacional } \\
\text { analítico } \\
\text { transversal }\end{array}$ \\
\hline $2 \quad$ & $\begin{array}{l}\text { Revisão } \\
\text { bibliográfica } \\
\text { narrativa e } \\
\text { estudo de } \\
\text { caso }\end{array}$ \\
\hline
\end{tabular}

3 Observacional analítico de coorte

\section{Resumo do estudo}

Este estudo pretendeu determinar se, no setor da produção de móveis numa zona da Turquia, os profissionais estavam ou não expostos a determinados agentes químicos prejudiciais para a saúde. 261 trabalhadores preencheram questionários e 210 concordaram em proporcionar uma amostra sanguínea para os doseamentos. Apesar da semiologia típica desta exposição ter sido encontrada em alguns trabalhadores, não se encontraram diferenças estatisticamente significativas entre os expostos e o grupo de controlo. A maioria desconhecia que estava exposto a solventes. Os autores supõem que o tabagismo poderá ter sido uma variável confundidora.

O autor estudou uma empresa do setor constituída por 10 funcionários; para além de descrever o processo produtivo, tipos de postos, maquinaria utlizada e fazer avaliação de riscos; também incluiu noções sobre higiene e segurança e legislação aplicável a este setor profissional.
Este estudo pretendeu investigar se a exposição aos derivados da madeira poderia promover alergias mediadas pela imunoglobulina $\mathrm{E}$, comparando trabalhadores da indústria da madeira (pinheiro e faia)- 1506 elementos- com um grupo controlo (195 indivíduos). Explorou também as associações entre a exposição, sensibilização e os sintomas respiratórios. Não se encontraram diferenças estatisticamente significativas, ainda que a sensibilização tenha demonstrado alguma relação de dependência com a exposição.

$4 \quad$ Observacional analítico transversal

\section{Este estudo pretendeu investigar a relação entre a semiologia respiratória e dermatológica e o} contato com derivados da madeira de uma espécie específica ("árvore da borracha"), produtora de latex. Foram estudados 103 trabalhadores da indústria da madeira e 76 empregados de escritório (como grupo de controlo). Os autores concluíram que os trabalhadores expostos apresentavam maior prevalência de sibilos, tosse, alterações na espirometria e até asma, além de maior prevalência de sintomas dermatológicos; por vezes numa associação dose-dependente. Contudo, alguns agentes químicos utilizados neste setor profissional também poderiam apresentar semiologia equivalente. móveis de uma zona da Dinamarca, com 6 anos de diferença, para a generalidade das fábricas avaliadas; no total avaliaram-se 2303 trabalhadores e fizeram-se 2358 doseamentos. Os autores concluíram que existiu uma melhoria generalizada das condições de trabalho a este nível, ainda que seja possíveis mais alterações, com particular destaque para a ventilação, técnica de limpeza e uso adequado do ar comprimido. 
O autor, além de fazer uma revisão bibliográfica sobre os efeitos para a saúde associados à narrativa e exposição de partículas de madeira, também realizou em estudo de caso que incidiu num estudo de trabalhador numa carpintaria de um hospital. As condições de trabalho foram avaliadas mediante caso check-list e por observação direta do trabalhador; este também preencheu um questionário.

$7 \quad$ Observacional analítico transversal

Este estudo pretendeu avaliar a associação entre a exposição aos derivados da madeira em carpinteiros e o respetivo risco cancerígeno (nomeadamente de adenocarcinoma das cavidades nasais e seios perinasais). A população estudada consistiu num grupo de 60 carpinteiros. Os autores concluíram que estes profissionais apresentam um risco oncológico superior.

8

Este estudo pretendeu avaliar a exposição aos derivados da madeira e respetivos efeitos na saúde para os trabalhadores, numa zona da Turquia; foram estudados 328 trabalhadores e 328 controlos. Os autores concluíram que a exposição aos derivados da madeira está associada a alterações da função respiratória.

9

Este estudo pretendeu avaliar a exposição a monoterpenos entre trabalhadores da indústria de produção de móveis, numa zona da Dinamarca; foram estudados 161 trabalhadores de 17 fábricas de móveis de pinho. Os autores concluíram que a exposição aos monoterpenos poderá ser atenuada através do melhoramento da circulação de ar/ ventilação.

Observacional descritivo

Este estudo pretendeu avaliar o perfil dos trabalhadores e as condições de trabalho nas marcenarias de uma zona do Brasil, através da aplicação de um questionário aos trabalhadores e da avaliação direta das condições de trabalho pelos autores, através de uma amostra de 42 marceneiros provenientes de 17 empresas. Os autores sintetizaram os principais problemas destes trabalhadores, tecendo também algumas considerações relativas a segurança e higiene, bem como acidentes de trabalho e o papel dos proprietários no melhor funcionamento da saúde ocupacional.

11 Observacional analítico transversal

Este estudo pretendeu avaliar os efeitos respiratórios em funcionários da indústria de produção de móveis numa zona da Tailândia, utilizadores da "árvore-da-borracha", numa amostra de 89 trabalhadores. Os autores verificaram que existiu uma maior prevalência de sintomas de irritabilidade nasal e alterações nas provas de função respiratória nos indivíduos expostos a maiores concentrações de derivados desta madeira.

12 Observacional analítico de coorte

Este estudo pretendeu avaliar a exposição aos derivados da madeira em 10 empresas de processamento de madeira, nos EUA, juntamente com uma avaliação dos sintomas respiratórios apresentados pelos trabalhadores, ao longo de 5 anos; de realçar que os resultados foram estratificados por subsetor/ máquina.

13 Observacional analítico de caso-controlo

Este estudo indiano teve o objetivo de avaliar os efeitos dos derivados da madeira no aparelho respiratório dos carpinteiros; para tal usou uma amostra de 150 carpinteiros e 150 controlos, todos não fumadores, entre os 18 e os 45 anos. Concluíram que alguns parâmetros espirométricos estavam diminuídos nestes profissionais, de forma estatisticamente significativa.

14 Observacional descritivo

Este estudo avaliou 3 marcenarias numa zona do Brasil (com uma amostra de 23 marceneiros), com destaque para o eventual desconforto térmico, ruído, iluminância, vibrações, agentes químicos e poeiras; através da aplicação de um questionário semiestruturado e fazendo destrinça entre os diversos setores/ máquinas.

Este estudo utilizou uma mostra de 80 carpinteiros, selecionados de uma população de 1119 profissionais; destes foram apenas admitidos 60 porque 20 não apresentavam espirometria ou anamnese completa. Os autores concluíram que $44 \%$ da amostra apresentava hipoacusia, em $74 \%$ dos casos de forma bilateral; esta também se demonstrou mais frequente em idades mais avançadas e em indivíduos com maior número de anos expostos ao ruído.

Quadro 2: Principais madeiras utilizadas, áreas geográficas de origem, principais utilizações e principais efeitos na saúde assinalados na bibliografia consultada.
Tipo de
Área geográfica
Utilizações (alguns exemplos)
Principais efeitos na saúde

\section{madeira}

Amieiro

Europa, América do

Brinquedos, vassouras

Dermatite

Norte e oeste asiático 


\begin{tabular}{|c|c|c|c|}
\hline Faia & $\begin{array}{l}\text { América do Norte e } \\
\text { Europa }\end{array}$ & $\begin{array}{l}\text { Móveis, pasta de papel e papel, bobinas, } \\
\text { vassouras, revestimentos de chãos, contraplacado }\end{array}$ & $\begin{array}{l}\text { Dermatite, rinite, asma, cancro } \\
\text { nasal }\end{array}$ \\
\hline Vidoeiro & $\begin{array}{l}\text { EUA, Canadá e } \\
\text { Europa }\end{array}$ & Móveis, pasta de papel e papel & Dermatite \\
\hline $\begin{array}{l}\text { Cedro } \\
\text { vermelho do } \\
\text { oeste }\end{array}$ & $\begin{array}{l}\text { Costa este da América } \\
\text { do Norte }\end{array}$ & Materiais de construção e barcos & $\begin{array}{l}\text { Asma, dermatite de contato } \\
\text { alérgica, conjuntivite, rinite }\end{array}$ \\
\hline Douglásia & $\begin{array}{l}\text { Costa este da América } \\
\text { do Norte e Europa }\end{array}$ & Materiais de construção, chãos, móveis e barcos & $\begin{array}{l}\text { Dermatite de contato, } \\
\text { diminuiçãa da função } \\
\text { respiratória }\end{array}$ \\
\hline Abeto & $\begin{array}{l}\text { EUA, Canadá e } \\
\text { Europa }\end{array}$ & Materiais de construção, móveis e contraplacado & Dermatite, rinite, asma \\
\hline Cicuta & América do Norte & Móveis & $\begin{array}{l}\text { Dermatite de contato, } \\
\text { diminuição da função } \\
\text { respiratória }\end{array}$ \\
\hline Lariço & $\begin{array}{l}\text { Europa e América do } \\
\text { Norte }\end{array}$ & Molduras, chãos e barcos & Dermatite de contato alérgica \\
\hline Mogno & África & Móveis, barcos, molduras & Dermatite \\
\hline Bordo & \multirow{4}{*}{$\begin{array}{l}\text { Europa e América do } \\
\text { Norte }\end{array}$} & Móveis & Rinite, asma \\
\hline Carvalho & & Móveis e folhas de madeira & Cancro nasal \\
\hline Pinho & & $\begin{array}{l}\text { Construção interior e exterior, pasta de papel e } \\
\text { papel }\end{array}$ & Dermatite, rinite, asma \\
\hline Álamo & & $\begin{array}{l}\text { Contraplacado, fósforos, brinquedos, pasta de } \\
\text { papel e papel }\end{array}$ & Dermatite, rinite \\
\hline Pau-rosa & América do Sul e Ásia & Folhas de madeira e móveis & Dermatite de contato alérgica \\
\hline Teca & Ásia, África e Índias & Navios, móveis e chãos & Dermatite \\
\hline Nogueira & Europa e EUA & Móveis e painéis decorativos & Dermatite, rinite, asma \\
\hline Teixo & $\begin{array}{l}\text { Europa, Ásia e Norte } \\
\text { de África }\end{array}$ & Esculturas e móveis & Dermatite 6 \\
\hline
\end{tabular}

(1)Santos M.: Licenciada em Medicina; Especialista em Medicina Geral e Familiar; Mestre em Ciências do Desporto; Especialista em Medicina do Trabalho; Presentemente a exercer nas empresas Medicisforma, Clinae, Servinecra e Serviço Intermédico; Diretora Clínica da empresa Quercia; Diretora da Revista Portuguesa de Saúde Ocupacional on line

(2)Almeida A.: Mestre em Enfermagem Avançada; Especialista em Enfermagem Comunitária; Pós-graduado em Supervisão Clínica e em Sistemas de Informação em Enfermagem; Docente na Escola de Enfermagem, Instituto da Ciências da Saúde- Porto da Universidade Católica Portuguesa; Diretor Adjunto da Revista Portuguesa de Saúde Ocupacional on line

Santos M. Almeida A., Principais riscos e fatores de risco ocupacionais dos marceneiros e carpinteiros, bem como doenças profissionais associadas e medidas de proteção recomendadas.Revista Portuguesa de Saúde Ocupacional on line. 2016, volume 1, 1-10. 